\title{
Retomando a Arqueologia da Imagem: entre iconografia clássica e cultura material
}

Resuming the Archaeology of Image: Between Classical Iconography and Material Culture ${ }^{1}$

Gilberto da Silva Francisco*

Haiganuch Sarian ${ }^{* *}$

Fábio Vergara Cerqueira ${ }^{* * *}$

\section{Resumo}

$\mathrm{O}$ artigo retoma o debate sobre a Arqueologia da Imagem sob duas direções: a primeira é a apresentação do conceito, e a segunda é a proposta de seu desenvolvimento a partir da associação entre imagem e cultura material. Nesse sentido, discutimos dois elementos básicos no tratamento arqueológico das imagens, circunstanciado pela noção de cultura material: os conceitos de suporte e de contexto. Por fim, dialogando com esse debate teórico, apresentamos um estudo de caso: a inserção mediterrânica de algumas imagens presentes em um objeto - a ânfora de Mississípi 1977.3.115, atribuída ao Pintor de Nicóxeno.

Palavras-chave: Arqueologia da Imagem; ceramologia grega; suporte; contexto.

\begin{abstract}
This paper resumes the debate on the Archaeology of Image from two directions: the first is the presentation of the concept, and the second is the proposal for its development based on the association between image and material culture. In this sense, we discuss two basic elements in the archaeological treatment of images, based on the notion of material culture: the concepts of support and context. Finally, considering the previous theoretical debate, we present a case study: the Mediterranean introduction of some images of a particular object - the amphora of Mississippi 1977.3.115 attributed to the Nikoxenos Painter.

Keywords: Archaeology of Image; Greek ceramology; medium; context.
\end{abstract}

\footnotetext{
* Universidade Federal de São Paulo (Unifesp), Guarulhos, SP, Brasil. gisifran@gmail.com <https:// orcid.org/0000-0002-9615-4922>

** Universidade de São Paulo (USP), Museu de Arqueologia e Etnologia (MAE), São Paulo, SP, Brasil. haigasarian@gmail.com <https://orcid.org/0000-0001-5360-8130>

*** Universidade Federal de Pelotas (UFPel), Pelotas, RS, Brasil. fabiovergara@uol.com.br <https:// orcid.org/0000-0001-8864-7762>
} 
A imagem figurativa em seus diferentes suportes é um dos objetos mais recorrentes dos estudos arqueológicos ligados à compreensão das sociedades do Mediterrâneo Antigo. As abordagens utilizadas para os estudos das imagens são variadas e, associadas a elas, constituiu-se um campo entre a Arqueologia, a Filologia e a História da Arte, geralmente bastante independente, caracterizado como Estudos Iconográficos (que chamaremos aqui de Iconografia Clássica), ${ }^{2}$ campo que foi sendo estruturado em torno do forte interesse pela imagem das sociedades antigas. Por exemplo, no que se refere à escultura grega e romana, a imagem já era foco de interesse desde o Renascimento, tendo contribuído também como base para a reflexão sobre o discurso plástico que se desenvolvia a partir do século XV. Em outro domínio, o das imagens em vasos de cerâmica produzidos por cidades gregas, desde o século XVIII desenvolveu-se um amplo interesse estético que deslocava os vasos de suas funções originais e os posicionava no campo das artes e, dessa forma, também os incluía na Iconografia Clássica.

Essa prática foi sendo cada vez mais estendida a imagens com suportes diferentes (além das esculturas e relevos e das figuras sobre os vasos de cerâmica, as imagens presentes em moedas, mosaicos e pinturas parietais, entre outros). E foi nesse sentido que surgiram grandes projetos acadêmicos de constituição de repertórios que também apresentavam imagens, seja em suportes específicos como os espelhos na série Corpus Speculorum Etruscorum (CSE) e os vasos de cerâmica na série Corpus Vasorum Antiquorum (CVA), até o interesse concentrado diretamente no registro imagético, em vários suportes, como o Lexicon Iconographicum Mythologiae Classicae (LIMC) (Sarian, 1996; 1998/1999), que seguiam modelos já bem estabelecidos de grandes repertórios de textos, como a série de edições especializadas em publicações de traduções comentadas de textos gregos e latinos como a Loeb Classical Library, no registro literário, e as séries Corpus Inscriptionum Graecarum (CIG), Corpus Inscriptionum Latinarum (CIL), e Inscriptiones Graecae (IG), no campo da Epigrafia - todos projetos iniciados já no século XIX.

Ao longo dos séculos XX e XXI, a Iconografia Clássica foi caracterizada por alguns elementos recorrentes, tais como a abordagem filológica, que promovia constantemente intepretações das imagens a partir de questões ou temas próprios da tradição textual; uma espécie de genealogia de modelos iconográficos, buscando-se certa unidade diacrônica; a constituição de uma hierarquia e a ideia de influência da "grande arte" sobre as "artes menores"; e a identificação de elementos diacríticos, como atributos e inscrições, para a identificação das personagens (Sarian, 1999, p. 70). Nesse sentido, deve-se notar que a observação da 
imagem em relação ao texto tornou-se um dos elementos mais importantes da interpretação das imagens relacionadas às culturas "clássicas".

Se, por um lado, a crítica à aproximação direta entre tradição textual e tradição imagética era desenvolvida já no fim do século XIX (Sarian, 1999, p. 70), a abordagem que compreende a imagem como um tipo de texto, tendendo à abordagem semiótica baseada na compreensão dos símbolos, e o registro imagético como algo que possa ser lido, ainda são bastante influentes. E, por mais metafórico que isso possa parecer, a influência dessa prática de sobreposição do texto à imagem produz certo deslocamento de aspectos da imagem, tais como a sua materialidade. Por exemplo, a influente obra Homero e os artistas, de Anthony Snodgrass, apresenta um capítulo intitulado "Aprendendo a ler no escuro", no qual a "leitura" das imagens em vasos de cerâmica dos séculos IX e VIII a.C. dá-se no "escuro", não porque as imagens sejam pouco claras, mas porque é difícil identificar quais especificamente são as personagens presentes nelas (Snodgrass, 1998, p. 12-39).

O objetivo aqui não é construir uma crítica das abordagens da imagem a partir dos paralelos com o texto, de sua caracterização como texto, ou do interesse evidentemente temático em suas interpretações; mas é refletir sobre os aspectos materiais relacionados à imagem e como, a partir da abordagem que começa a ser construída em torno da "Arqueologia da Imagem", outros significados da imagem podem ser mobilizados a partir da compreensão da materialidade da imagem, e como ela influencia até mesmo na elaboração do tema. Nesse sentido, é importante pensar antes sobre o próprio conceito de Arqueologia da Imagem e, depois, desenvolver alguns elementos associados a ele.

\section{A Arqueologia da Imagem}

Antes de tudo, é preciso notar que Arqueologia da Imagem é um conceito polissêmico e que a variedade contida nele está relacionada principalmente ao termo Arqueologia. Em uma das propostas de sua caracterização, a imagem é relacionada às abordagens da disciplina arqueológica e às suas práticas, como a seriação, análise laboratorial etc.; ou associada ao conceito de cultura material, que não é exclusivo, mas consistentemente ligado à Arqueologia (Bellan, 2018, p. 34). A ideia de Arqueologia da Imagem foi cunhada no seio da Arqueologia francesa na década de 1970 e sintetizada em um artigo referencial escrito por Philippe Bruneau, "De l'image" (Bruneau, 1986), ${ }^{3}$ com alguns desenvolvimentos, por exemplo, na compreensão da iconografia do mito e da religião (Sarian, 1999; Sarian, 2005). 
Em outras propostas, a imagem está relacionada ao termo "arqueologia", mas de forma bastante ampla: não só aquele próprio da acepção antiga, archaiología como uma narrativa antiga, sobre o arché (o princípio, a origem no tempo ou no espaço, e também o espaço delimitado onde originalmente estabeleceu-se o poder), ${ }^{4}$ o que se utilizou de forma metafórica em vários campos, constituindo-se, assim, "arqueologias da imagem" ligadas ao tratamento de documentação imagética variada, como a fotografia e a pintura (Córdova, 2000; Büchsel, 2003; Cohen, 2003, p. 387; Oberschelp, 2007, p. 45; Junca, 2019, p. 119; Yelles, 2019), e em alguns casos, em diálogo com a noção de arqueologia proposta principalmente por Michel Foucault (Visagie, 2000; Chérel; Saussier, 2008, p. 30 e Després-Lonnet, 2014, p. 34); $;^{5}$ mas também no sentido presente em outros autores como Friedrich Nietzsche, Walter Benjamin, Carl Einstein e Aby Warburg (Echeto, 2016).

Tais propostas de caracterização da Arqueologia da Imagem não são complementares. $\mathrm{O}$ conceito de arqueologia diverge bastante, e a imagem parece ser o ponto em comum. Entretanto, temos imagens em domínios muito específicos: de um lado, a Iconografia Clássica, do outro, imagens de diferentes épocas e suportes, além de pressupostos teóricos bastante específicos. E, nesse sentido, é preciso dizer que o domínio aqui tratado é aquele correspondente à disciplina arqueológica, no qual a Arqueologia da Imagem é um conceito bastante circunscrito à academia francesa e, mesmo nela, não é amplamente utilizado. O conceito aparece explicitamente em publicações de Philippe Bruneau e de Pierre-Yves Balut, como no artigo "De l'image" de Bruneau, em um tópico de conclusão, a partir de uma distinção básica entre fazer Arqueologia pela imagem (o uso instrumental da imagem) e fazer Arqueologia da Imagem (Bruneau, 1986, p. 284-285), ${ }^{6}$ e a integração da Iconografia Clássica à Arqueologia se faz não como um domínio independente, mas comprometida com a disciplina (Bruneau, 1986, p. 285). De maneira mais ampla, a Arqueologia da Imagem é caracterizada como uma síntese da Iconografia Clássica, e seu debate se concentra em questões da teoria da imagem.

Como visto, o aspecto temático, conteudista, dominou o interesse sobre as imagens no campo da Iconografia Clássica, marginalizando a integração de determinados aspectos materiais como o suporte e o contexto das imagens. Trazer a imagem para o campo da Arqueologia talvez signifique também pensar a imagem como cultura material, aqui pensada não apenas como um sinônimo de objeto ou artefato, mas alçando a esfera da apropriação física da natureza pelos grupos humanos. E, nesse sentido, serão desenvolvidos aqui dois 
aspectos fundamentais da noção de cultura material na discussão arqueológica - as noções de suporte e de contexto.

\section{A NoÇÃo DE SUPORTE: O MEDIUM E A MENSAGEM}

Os mais recentes debates sobre suporte indicam que, mais do que um elemento sobre o qual a informação é apresentada, ele contribui significativamente para a sua constituição mais complexa. Essa noção mais profunda de suporte vem sendo discutida, com resultados interessantes, a partir da noção de medium, no âmbito da chamada Teoria dos Meios (Media Theory), organizada na década de 1960 tendo como figura central o teórico da comunicação Marshall McLuhan. Na sua obra Understanding Media: The Extensions of Man, publicada em 1964, aparece a ideia “o meio (medium) é a mensagem”, que seria amplamente retomada e atualizada (Logan, 2010; Ciastellardi; Almeida; Scolari, 2011). E é sobre essa associação entre suporte, então compreendido como medium, e as imagens (incluindo aspectos desde sua criação até o fenômeno da comunicação associado a elas) que gostaríamos de insistir.

Ao considerar o suporte, também é possível rediscutir algumas hierarquias como as que aparecem em estudos de imagem entre os aspectos materiais que organizam o suporte e a imagem social/cultural pensada, sobretudo, como veículo de informação ou componente de um sistema cultural complexo. É assim, por exemplo, na obra de Erwin Panofsky (1976), na qual o nível mais claramente caracterizado pelos aspectos materiais, o pré-iconográfico, é um passo inicial de um percurso que objetiva, passando pelo nível iconográfico, chegar à iconologia; tratando-se, dessa forma, não do abandono dos aspectos materiais no âmbito da interpretação das imagens, mas de constituição de certa hierarquia entre as suas características materiais e seu tema, ${ }^{7}$ o que influenciou em certa medida a Iconografia Clássica. Por exemplo, em uma obra intitulada Greek sculpture and the problem of description, de Alice A. Donohue, os três níveis panofskyanos são explicitamente evocados nas interpretações (Donohue, 2005, p. 50); ${ }^{8}$ e, cabe dizer, o suporte é elemento secundário.

Já a Teoria dos Meios não influenciou muito a Iconografia Clássica; ${ }^{9}$ entretanto, algo do debate sobre o medium, em termos de suporte, apareceu timidamente em algumas reflexões sobre a Arqueologia da Imagem: “é, sem dúvida, através da rigorosa descrição e interpretação, métodos arqueológicos científicos por excelência, que se fundamenta uma Arqueologia da Imagem, ao abordar as várias categorias de cultura material (vasos, esculturas, relevos, 
moedas etc.) com todas as suas especificidades, enquanto suporte de imagens" (Sarian, 2005, p. 13).

Sobre as especificidades relacionadas à articulação material da imagem (aqui compreendida como suporte/medium), elas podem ser observadas desde o âmbito da produção até a recepção (que será tratada mais adiante) específica dos objetos "portadores de imagens" (Sarian, 1999, p. 70). Os temas do amplo repertório de imagens correspondente à Iconografia Clássica eram articulados a partir de arranjos muito específicos: por exemplo, os artesãos ceramistas deveriam lidar com a lógica do aspecto gráfico das imagens sobre a superfície de um objeto curvilíneo e com várias interrupções e transições no espaço disponível; já o escultor deveria ocupar-se da lógica da tridimensionalidade, aspectos das cores sobre a superfície esculpida, a localização na paisagem etc. $\mathrm{Ou}$ seja, cada domínio da produção figurativa apresentaria um conjunto de soluções técnicas que produziria figuras específicas, mesmo que o tema fosse o mesmo.

Assim, para além de uma fase primeira de descrição das imagens os aspectos materiais que as estruturavam também oferecem elementos importantes para se pensar sobre questões como a restrição ou uso de determinada informação (é o caso da cor), e mesmo sobre as quantidades de imagens produzidas em cada domínio produtivo (ou seja, o ritmo de produção em oficinas ceramistas e o das oficinas que produziam escultura em materiais variados), mas também a própria avaliação social do objeto e de seu produtor. ${ }^{10}$

Esquema 1 - Imagem, Iconografia Clássica e Arqueologia da Imagem.

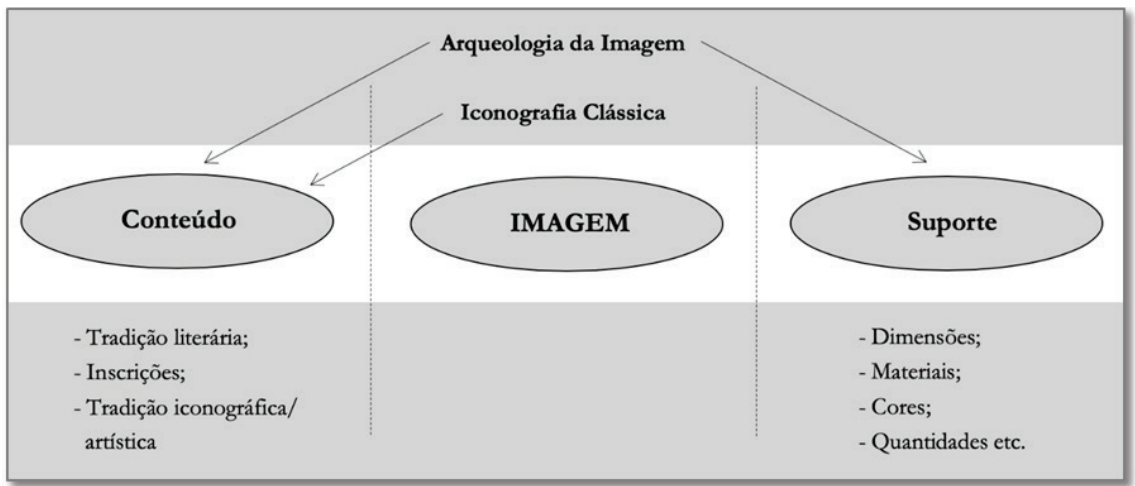

Nesse sentido, é possível notar que, para além de simples elemento de aplicação da imagem, o suporte é elemento fundamental e, se considerado, 
pode indicar alguns aspectos que a observação generalista não alcança. Por exemplo, o significado de uma imagem é constituído já nos seus elementos básicos, considerados pré-iconográficos na análise de Panofsky, mas que indicam certas direções para uma observação mais contextualizada. O suporte, assim, é um dos elementos fundamentais para a construção do significado da imagem, que também pode ser observado de forma contextualizada. Além disso, o suporte aparece como um elemento de conexão entre dois âmbitos importantes da construção do significado: o autor e o receptor da mensagem. Assim, no âmbito da Arqueologia da Imagem, o suporte tem o mesmo peso para a compreensão dos significados das imagens (ver Esquema 1).

\section{A IMAGEM CONTEXTUALIZADA: ENTRE PRODUÇÃO, CIRCULAÇÃO E RECEPÇÃO}

Contexto parece ser outro conceito problemático. Extremante aberto, aqui ele será observado com base nas claras conexões com a ideia de suporte, e desenvolvido a partir de três noções diferentes, mas complementares: os contextos histórico, sistêmico e arqueológico. Não se trata, dessa forma, das ideias de ciclo de vida do objeto, agência ou cadeia operatória isoladamente, mas da compreensão da constituição de significado das imagens a partir dos arranjos específicos que elas formavam, incluindo a sua historicidade.

As relações entre imagem (como referência) e referente, a proposta do autor (o artesão ou artista) e seu universo cultural são apenas parte dos significados potencialmente relacionados às imagens. Assim, se consideramos a imagem um tipo específico de informação, o significado relacionado a ela também depende do contexto para ser compreendido. Entretanto, é importante compreender a própria noção de contexto para pensar sobre a sua implicação na compreensão da imagem contextualizada.

Quanto aos três qualificativos aqui evocados (sistêmico, histórico e arqueológico), evidenciam recortes disciplinares propostos em campos como Linguística, Antropologia, História e a Arqueologia, ${ }^{11}$ mas esses são apenas algumas possibilidades de um conjunto mais amplo e numeroso (Fetzer, 2012, p. 105). Entretanto, parece que o debate teórico mais desenvolvido é dominado pela Linguística, para a qual - é importante afirmar - a própria discussão sobre o conceito aprece ainda como necessidade recente (Fetzer, 2012, p. 9). Nesse sentido, o contexto aparece como um elemento crítico à independência exacerbada do objeto; entretanto, ao ser apropriado como um elemento 
fundamental, criticou-se o chamado "império do contexto" em alguns debates, como aquele relacionado a "agência" (Gell, 1998, p. 4-5).

Contexto, dessa forma, define a relação entre um objeto e outros níveis que ele forma ou associados a ele. Considerando o próprio termo, o objeto (o texto) é observado para além de sua complexidade intrínseca ou interna, incluindo os elementos que não são explicitamente apresentados nele. E, considerando isso, há uma primeira questão importante sobre o ambiente de relação que define o contexto: o âmbito ou âmbitos que interessam para a sua compreensão, que geralmente são definidos a partir dos recortes disciplinares (a ideia de contexto histórico e arqueológico, por exemplo), ou mais precisos (com a ideia de um contexto sistêmico). Nesse sentido, a ideia de um contexto histórico pressupõe a conexão entre determinado objeto e sua historicidade compreendida a partir das relações entre ele e os campos da cultura, sociedade, economia, política etc., próprios de uma época. Já o contexto sistêmico pressupõe as relações entre o objeto escolhido e a sua cadeia operatória (paisagens e ações ligadas às dinâmicas de sua produção, uso e descarte), enquanto o contexto arqueológico pressupõe as relações entre o objeto encontrado em determinado "local de achado" com aspectos paisagísticos e com outros objetos.

No que se refere à imagem contextualizada, seria possível pensar em esquemas complexos organizados entre as diferentes noções de contexto (sistêmico, histórico e arqueológico), mas de forma complementar; ou seja, o significado da imagem não é pensado a partir apenas das condições históricas de determinado grupo, mas também das condições específicas que precisam a lógica da produção, circulação e recepção desses objetos. Assim, o produtor de imagens as cria a partir de demandas socioculturais específicas (sua visão de mundo, arranjos comerciais, aspectos indenitários etc.) que seriam mais bem compreendidos considerando a abordagem histórica dessas sociedades. Entretanto, elementos como as condições específicas do trabalho (por exemplo, sua técnica) são também importantes para a reflexão do cenário de criação de um repertório figurativo, e esses são, geralmente, elementos pensados com mais profundidade na pesquisa arqueológica sensível às questões do contexto sistêmico.

E, ainda, o contexto arqueológico, pensado como o contexto posterior ao uso primário ou original dessas imagens, correspondente à experiência do objeto deslocado das dinâmicas sociais pensadas como contexto histórico ou sistêmico, oferece a compreensão de forma mais precisa da relação entre o objeto/fonte (neste caso, a imagem) e as dinâmicas sociais relacionadas à sua produção, circulação e consumo originais. É a rigorosa compreensão do contexto 
arqueológico que informa, a partir do universo físico, circunstanciado pela noção de cultura material, as especificidades que informam o que consideramos contexto sistêmico e histórico. E a imagem, pensada como cultura material, também pode ser observada como uma balança que tem, de um lado, pesos próprios do contexto original em que ela foi produzida e consumida; e, do outro, o pesquisador que a encontra, cataloga, e propõe interpretações sobre ela. $\mathrm{O}$ contexto arqueológico, nessa metáfora, é o fiel da balança (ver Esquema 2).

De maneira geral, o contexto relacionado às imagens é efetivamente composto por elementos paisagísticos. É importante notar que havia imagens que tendiam à imobilidade (por exemplo, esculturas monumentais) e outras caracterizadas por sua ampla mobilidade e circulação (o caso das imagens em moedas e nos vasos de cerâmica). Nesses dois casos, elementos fundamentais de mediação entre as pessoas e as imagens eram baseados em diferentes estratégias: por exemplo, no caso das imagens "imóveis", elas deveriam ser observadas no local em que foram fixadas. Isso significa que elas compunham esquemas paisagísticos mais constantes. Assim, a interpretação de uma estátua de culto dependia da sua situação no santuário, e a interpretação de um relevo em lápide de alguma necrópole também agregaria potencialmente os elementos do lugar no seu significado. Além disso, essas imagens, dada a sua característica fixa, poderiam ser observadas por "espectadores" que se deslocavam até elas ou que sobre elas eram informados por relatos textuais (orais ou escritos), ${ }^{12}$ em representações figurativas em moedas, pequenos relevos ou estatuetas, vasos de cerâmica etc.

No caso das imagens móveis, seu significado era constituído por um processo bastante diferente. Observando os mapas de distribuição de moedas ou dos vasos de cerâmica, por exemplo, é possível notar que imagens produzidas por cidades gregas foram consumidas em regiões bastante distantes delas, considerando os mercados que as distribuíram em pontos variados do Mediterrâneo Antigo. Assim, vasos produzidos por cidades gregas foram encontrados em regiões distantes como a Península Ibérica, a Britânia e a Arábia, entre outras. Nesse caso, outro elemento fundamental deve ser considerado na compreensão do significado das imagens: seus “consumidores", já que não é possível que a mesma aptidão para o reconhecimento dos esquemas imagéticos e dos temas fosse a mesma nas cidades gregas e na Ibéria ou na Britânia. Muito possivelmente, os recortes culturais muito diversificados que esses objetos formavam interferiram nos significados a eles atribuídos. ${ }^{13}$ 
Esquema 2 - A Imagem e Contextos.

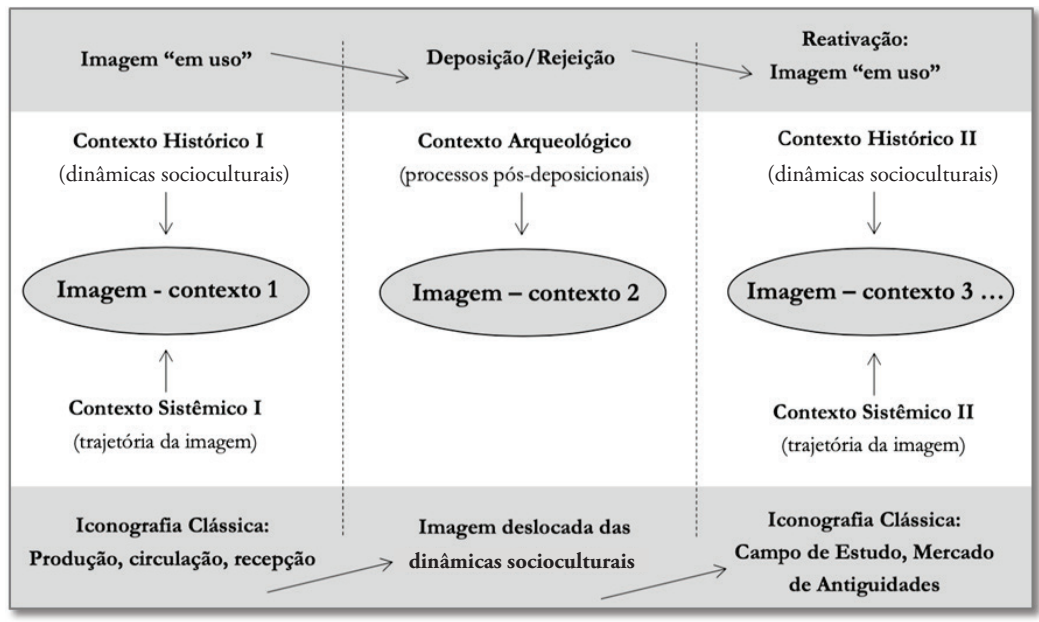

É possível, ainda, precisar mais esse cenário de recepção. Como visto, a recepção de uma imagem específica produzida por um artesão/artista do mundo grego poderia variar dependendo da dinâmica específica do contato com ela. Assim, um vaso ático consumido em Atenas apresentaria um cenário potencialmente mais apto para a compreensão mais profunda do significado proposto pelo artesão/artista. Entretanto, o mesmo vaso encontrado em regiões limítrofes como a Ibéria indica que a aptidão para a compreensão do significado atribuído originalmente pelo criador da imagem era relativamente pequena. Isso não significa que a compreensão fosse qualitativamente inferior. Ao contrário, novos e distintos significados poderiam ser acessados a partir de uma interação com a imagem que não previa o conhecimento específico de versões figuradas do mito, por exemplo.

Por fim, as condições específicas de imobilização das imagens podem indicar mesmo uma revisão de aspectos fundamentais do consumo visual; ou seja, partir da ideia segundo a qual imagens serviam para serem vistas. De maneira geral, o isolamento do objeto na pesquisa apresenta propostas de leitura e significados profundos que, se observados a partir dos contextos das imagens, poderiam ser, pelo menos, revisados. Por exemplo, as imagens na cidade, em um santuário ou em uma necrópole, eram imagens imobilizadas em contextos com ampla oferta de informação visual. Em um santuário, haveria as estátuas de culto monumentais, estatuetas e vasos de cerâmica, entre outros, como oferendas. A complexidade da paisagem criada apresentava potencialmente uma grande quantidade de imagens disponíveis. Além dos 
significados relacionados nessa possível variedade figurativa, a própria noção de consumo específico, como em uma paisagem "museológica", pode ser repensada. A questão de fundo é: qual era a lógica do consumo dessas várias imagens apresentadas em um mesmo espaço?

Outro elemento fundamental para se pensar no consumo visual das imagens na Antiguidade são as dinâmicas de imobilização em espaços fechados, tais como em depósitos votivos em santuários e no interior de tumbas. Muitas imagens materializadas em estatuetas de material variado, em moedas, em vasos de cerâmica, metais etc., foram imobilizadas em contexto que impedia o seu consumo visual. Se houve consumo visual, ele caracterizou ínfima parte da experiência de várias imagens que foram enterradas ou armazenadas em práticas votivas, e elas passaram milhares de anos dessa forma, sendo redescobertas em escavações de leigos ou promovidas por arqueólogos.

Philippe Bruneau (1988, p. 20) dizia que a Epigrafia (um campo também bastante independente, muitas vezes pensado como uma disciplina em si) é o ponto de encontro entre a Filologia e a Arqueologia. Da mesma forma, a Arqueologia da Imagem pode ser vista como o ponto de encontro entre a Iconografia Clássica e a Arqueologia (ver Esquema 3); entretanto, essa é uma relação na qual a lógica da cultura material teria consequências mais amplas na abordagem das imagens.

Esquema 3 - Arqueologia da Imagem

(Arqueologia, Iconografia Clássica e Cultura Material).

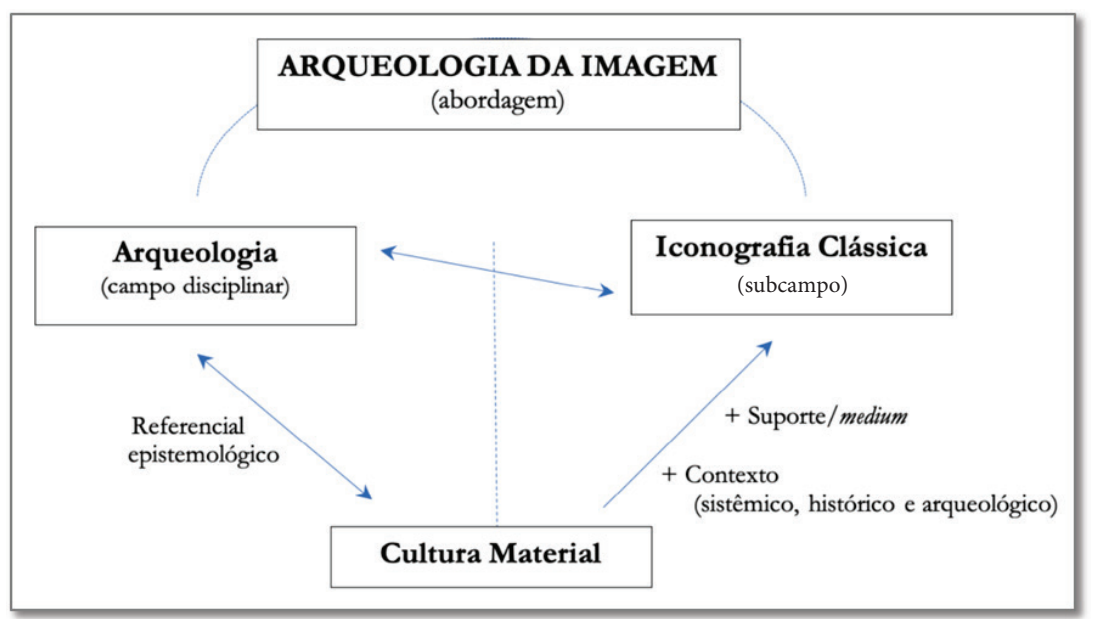


Já apresentamos alguns aspectos dessa proposta que concebe a imagem como cultura material, o que pode contribuir para uma nova perspectiva de abordagem das imagens, aqui pensada como Arqueologia da Imagem. Na sequência, apresentaremos um estudo de caso que busca recuperar alguns aspectos debatidos aqui como essenciais para a apresentação de novos aspectos interpretativos no âmbito da Arqueologia da Imagem, nomeadamente, o suporte e o contexto.

\section{UMA OBSERVAÇÃO DE IMAGENS EM CONTEXTO GLOBAL: O CASO DA ÂNFORA DE Mississípi 1977-3.115 DO Pintor DE Nicóxeno}

A partir deste ponto, apresentaremos um estudo de caso específico: a proposta de interpretação das imagens de um objeto com base nos elementos discutidos, visando constituir um exemplo de inserção mediterrânica ou "global” de um conjunto de imagens. ${ }^{14}$ Trata-se da figuração da deusa Atena em uma ânfora de tipo panatenaico em figuras vermelhas atribuída ao artesão caracterizado como Pintor de Nicóxeno (Figuras 1 e 2). ${ }^{15}$ No que se refere às interpretações dessas imagens, o foco foi estabelecido sobre a explicação das cenas (Atena armada em contexto de sacrifício) e as relações evidentes com o referencial panatenaico - a imagem da deusa Atena nas ânforas panatenaicas (Neils, 1992, p. 152; Lessa, 2004, p. 133-135). Entretanto, as relações entre o vaso-modelo e essa variação, se observadas a partir da lógica de suporte e de contexto, parecem indicar mais precisamente os possíveis significados dessas imagens.

A forma do vaso também informa algo sobre as imagens: não apenas as figuras dialogam com um modelo bem estabelecido de figuração da Atena panatenaica (Figura 3), mas a forma do vaso confirma essa relação. Assim, há um evidente interesse em apresentar uma variação que dialogasse com uma referência já bem constituída na época da produção desse vaso. Não se trata de uma réplica, mas de uma produção paralela com evidentes pontos de contatos e desvios: por exemplo, o vaso tem dimensões menores (sua altura é 43 $\mathrm{cm}$, enquanto a média das ânforas panatenaicas era de $60 \mathrm{~cm}$ ); a técnica é de figuras vermelhas em contraposição às figuras negras; a deusa Atena aparece nas duas faces, diferentemente do modelo panatenaico que reservava uma das faces à figura atlética etc. Ou seja, os desvios são claros, mas estabelecem um diálogo preciso com a figuração das ânforas panatenaicas, mais do que simplesmente as imitar. 
Entre as duas faces do vaso há uma ideia de sequência: em uma delas, Atena está associada a seus armamentos, mas não está paramentada, diante do altar com sangue que escorreu, denunciando o momento posterior ao sacrifício animal, e uma labareda no topo do altar indica a fase da holokausta (Figura 1). $\mathrm{Na}$ outra face, a deusa paramentada ainda se apresenta diante do altar, já sem labaredas, mas com as marcas do sangue do animal sacrificado (Figura 2). Assim, um momento é subsequente ao outro, e a dúvida seria estabelecer qual era o início e qual o fim dessa narrativa que se desenvolve entre as duas faces. Entretanto, considerando o interesse explícito em dialogar com a Atena panatenaica, é possível notar outros níveis de composição da narrativa.

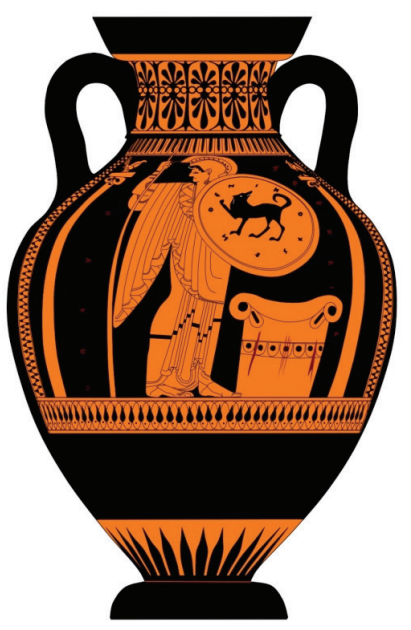

Figura 1 - Ânfora de tipo panatenaico em figuras vermelhas atribuída ao Pintor de Nicóxeno, c. 500 a.C., alt.: $43 \mathrm{~cm}$; Mississippi - University Museums, inv.: 1977.3.115 (face 1) - desenho de Gilberto da S. Francisco.

Figura 2 - Ânfora de tipo panatenaico em figuras vermelhas atribuída ao Pintor de Nicóxeno, c. 500 a.C., alt.: $43 \mathrm{~cm}$; Mississippi - University Museums, inv.: 1977.3.115 (face 2) - desenho de Gilberto da S. Francisco.

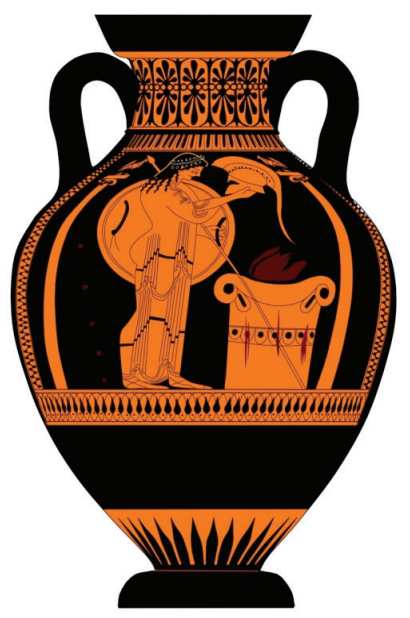


A Atena panatenaica era um modelo já bem constituído na transição para o século $\mathrm{V}$ a.C., caracterizado pela figura da deusa em atitude de ataque, chamada de Promakhos. ${ }^{16}$ Ali, Atena está paramentada para o combate e seu gestual indica atitude agressiva (Figura 3). Dessa forma, é possível pensar que a Atena panatenaica fosse um momento a ser considerado nessa sequência: (1) a deusa paramentando-se para o combate em ambiente religioso onde recebeu uma oferenda; (2) o ritual de sacrifício termina e a deusa paramenta-se (Figura 2); e (3) ela parte para o combate (a própria Atena panatenaica - Figura 3); ou a ordem inversa, ${ }^{17}$ ou seja, três momentos constituídos a partir da relação entre as duas faces desse vaso do Pintor de Nicóxeno e um modelo bem constituído de tradição artesanal e também de conhecimento público, sobretudo na Ática.

Figura 3 - Ânfora panatenaica atribuída ao Pintor de Cleofrades (próximo), c. 500-480 a.C., alt.: $63.5 \mathrm{~cm}$; Toledo Museum of Art (Ohio), inv.: 1961.24, Francisco, 2012, cat. 128 - desenho de Gilberto da S. Francisco.

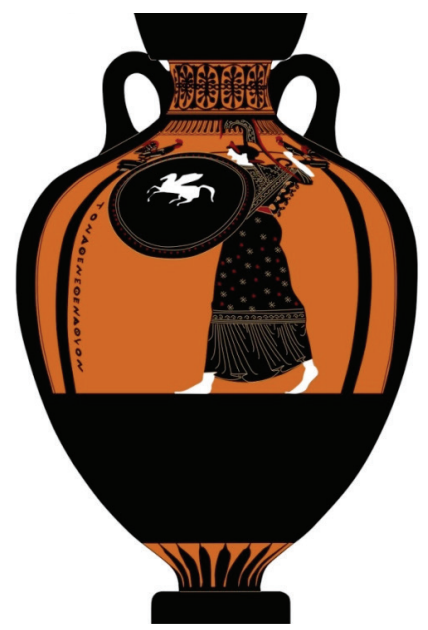

No âmbito da produção, apesar de o Pintor de Nicóxeno não ter produzido ânforas panatenaicas (é o que indicam os achados), ele atuou possivelmente próximo do Grupo de Leagros e parece ter sido "mestre" do Pintor de Eucarides, ambos ligados à produção de ânforas panatenaicas (ver Francisco, 2012, p. 290). E, na produção específica do Pintor de Nicóxeno, esse tipo de variação foi bastante explorado para além da ânfora de Mississípi. ${ }^{18}$ Ou seja, é possível notar que o Pintor de Nicóxeno conhecia bem o modelo panatenaico e que este o teria inspirado na produção das imagens do vaso de Mississípi, e de outros similares, 
que compunham derivações de ânforas panatenaicas junto a miniaturas e algumas cópias em figuras negras chamadas ânforas pseudopanatenaicas.

Quanto à compreensão mais ampla na região da Ática, a identificação desses níveis também poderia ser claramente estabelecida. Mesmo fora do ambiente de produção, onde as ânforas panatenaicas eram produzidas aos milhares, a paisagem do festival panatenaico produzia, a cada 4 anos, uma forte inserção de ânforas panatenaicas com a figura de Atena em uma das faces. $\mathrm{Ou}$ seja, elas compunham sazonalmente a paisagem local de maneira intensiva; e, a partir disso, poderiam compor um referencial fixo na memória dos habitantes da região; mas não somente ali, já que as ânforas panatenaicas eram entregues aos vencedores dos jogos atléticos provenientes de regiões variadas do mundo grego. Assim, logo depois do festival, havia certa dispersão desse conjunto de vasos em regiões variadas, mas em nenhuma delas havia uma concentração tão grande quanto na Ática, especialmente em Atenas, um ambiente potencialmente caracterizado pela clara compreensão do referencial panatenaico no seio da produção e da recepção imediata (Francisco, 2012, p. 218-219; 283-284; Francisco, 2013).

Entretanto, esse vaso não foi mantido em Atenas, mas longe dali - em uma cidade da Campânia, a etrusca Cápua, um contexto que apresenta situações bastante diferentes de recepção dessas imagens. Esse vaso era um objeto de fora, uma produção claramente estrangeira. É claro que a cerâmica ática foi consumida em larga escala na Península Itálica, incluindo a região da Etrúria, desde meados do século VI a.C., proporcionando até mesmo a produção local de formas áticas e formas etruscas que foram produzidas na Ática para suprir em grande medida o mercado etrusco (Spivey, 1991; Gill; Vickers, 1995). Ou seja, vasos de cerâmica áticos eram conhecidos na região; e, nesse sentido, é importante notar em que medida o referencial panatenaico era conhecido.

Seguindo a proposta original do Pintor de Nicóxeno, a familiaridade com o modelo panatenaico era a base para a compreensão das imagens dessa ânfora. Nesse sentido, é preciso considerar que os habitantes da Etrúria eram consumidores indiretos de ânforas panatenaicas, já que não participavam dos jogos panatenaicos, evento no qual eles eram obtidos mediante vitória em uma das provas; e que, por mais que as ânforas panatenaicas tenham sido encontradas na região da Etrúria, os achados em Cápua são pouco numerosos (apenas dois - Francisco, 2012, cat. 470 e 486), e datados do século IV a.C. Ou seja, parece que, ali, as imagens da Atena panatenaica não apresentavam um referencial tão sólido; e que, consequentemente, a interpretação dessas imagens não poderia pressupor o reconhecimento das referências exteriores que eram 
explícitas na região da Ática. Com isso, mesmo sem sabermos exatamente como essas imagens foram interpretadas entre os habitantes locais, é possível pensar em um cenário provável de referências no qual eles estavam inseridos para a compreensão específica dessas imagens.

Nota-se, nesse caso, que o significado das imagens é algo construído a partir de elementos variados. A forma do vaso é essencial para a compreensão de sua clara associação com um modelo bem constituído. Além disso, a dinâmica da sua recepção foi caracterizada por um ambiente no qual não haveria condições favoráveis para que a proposta do artesão fosse compreendida na sua profundidade; ou seja, ali o significado das imagens, muito provavelmente era diferente. O contexto é, portanto, elemento fundamental para a reflexão do enquadramento sociocultural dessas imagens.

Sobre a recepção de imagens produzidas na Grécia continental e insular em contexto italiota, há alguns exemplos que indicam claramente cenários de ressignificação; por exemplo, o caso de imagens das Erínias produzidas em contexto ático e etrusco. Na Ática, em imagens de vasos de cerâmica do século $\mathrm{V}$ a.C., elas foram consistentemente situadas na narrativa do julgamento de Orestes, presentes em cenas que se passam no Areópago em Atenas, elemento também encontrado na tradição textual, atribuindo a essas imagens um caráter religioso e político (Sarian, 2005, p. 79-118). Na Etrúria, o modelo iconográfico chega por meio da produção da Magna Grécia e assume um significado diferente: as Erínias foram associadas a entidades religiosas locais, Nathum e Vanth, em imagens de vasos, de espelhos e de relevos em urnas funerárias entre os séculos IV e II a.C. (Sarian, 2005, p. 79-118). Há, nesse sentido, o mesmo esquema figurativo respondendo a demandas diferentes entre o contexto ático e o etrusco. E, em um estudo sobre as imagens produzidas em contexto ático, italiota e etrusco sobre a contenda musical entre Apolo e Mársias, Fábio V. Cerqueira (2012, p. 102) apresenta uma síntese similar:

Por meio do fluxo entre as tradições orais, visuais e literárias - tradições interdependentes, com ritmos próprios e singularidades estéticas, temáticas e socioeconômicas -, vemos como o complexo mítico \{Atena-Mársias-Apolo / aulós-lýra\} se incorpora à memória cultural mediterrânica, marcando um acento de identidade grega, mas que, numa perspectiva transcultural, é assimilado e recriado em contextos diversos, como o contexto etrusco, contemporâneo ao mundo grego clássico, e o contexto imperial romano, quando vigorava a grande cultura greco-romana internacionalizada a partir da bacia do Mediterrâneo. 
Quanto ao modelo panatenaico especificamente, na região da Península Itálica sua recepção foi tímida. Ali, geralmente, os vasos panatenaicos eram associados ao espírito atlético e consistentemente imobilizados em contexto funerário. Mais que isso, há um conjunto de vasos produzidos nessa região que tinham a forma inspirada nas ânforas panatenaicas, mas com figuração alternativa, cuja imobilização e conteúdo figurativo eram amplamente associados ao contexto funerário. Um vaso nesse repertório italiota chama a atenção: trata-se de uma cópia de ânfora panatenaica produzida em Metaponto, com forma e programa figurativo muito similares: em uma das faces, a Atena panatenaica (Figura 4), e do outro, atletas correndo. As variações são poucas e sutis: por exemplo, a altura do vaso $($ c. $40 \mathrm{~cm})$, e não há a tradicional inscrição ton Athenethen athlon (Figura 3); entretanto, essas variações também são encontradas em vasos parecidos produzidos na Ática, como as ânforas pseudopanatenaicas (vasos muito similares, um pouco menores e sem a inscrição).

No caso dessa cópia de Metaponto, há uma variação importante: Atena é enquadrada entre os limites inferior e superior do painel, diferentemente do caso das ânforas panatenaicas, nas quais o capacete da deusa ultrapassa (em parte ou integralmente) o limite superior em todos os exemplares conhecidos. Esse desvio indica que esse vaso que dialoga com o modelo panatenaico foi produzido por um artesão que não estava efetivamente incluído na tradição presente nas oficinas áticas que criaram, aos milhares, figuras de Atena nas ânforas panatenaicas respondendo ao mesmo processo de delimitação da figura. Ou seja, mais do que uma discussão sobre os limites da figura no painel, esse exemplo indica a relação de um artesão operando na Magna Grécia em relação ao modelo panatenaico e, por extensão, a dinâmica dos diálogos com as oficinas áticas. Dessa forma, apesar de a imagem ser praticamente a mesma, e também a forma do vaso, a técnica indica um desvio importante que afasta o artesão do sul da Itália do processo produtivo específico das oficinas áticas.

Além da mensagem proposta pelo Pintor de Nicóxeno e sua recepção em Cápua, provavelmente distante do conjunto de referências básicas para a compreensão de seu significado original, a circulação dessas imagens coloca ainda outra questão sobre o cenário de comunicação no qual elas estavam inseridas. Parece que o pintor considerava que a recepção do vaso fosse feita em ambiente ático. Indicativo disso são, além das imagens que demandam o conhecimento de um referencial ático, as inscrições relacionadas às imagens. Na base do vaso há um graffiti (a letra kappa, cujo significado não é conhecido); e, no bojo, há inscrições pintadas junto às imagens. Uma delas faz referência à deusa, 
Athenaia, em verniz rubro (ver Figuras 2 e 5), uma tradicional prática de replicar o conteúdo figurativo com uma inscrição.

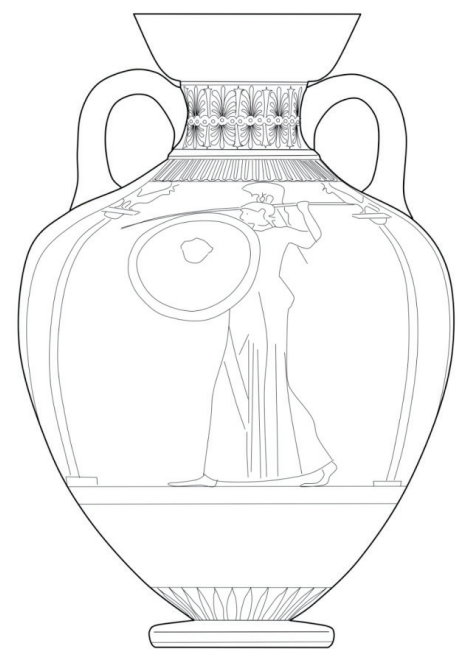

Figura 5 - Inscrições da ânfora Mississípi 1977.3.115 isoladas (de cima para baixo): iioloii (kalos); Athenaia; Nikoxsenos; kaloii (kalos) - desenho de Gilberto da S. Francisco.
Figura 4 - Cópia italiota de ânfora panatenaica atribuída ao Pintor de Pisticci, século V a.C., alt.: 40,5 cm; National Archaeological Museum of Metaponto, inv. 310.897 - desenho de Gilberto da S. Francisco.

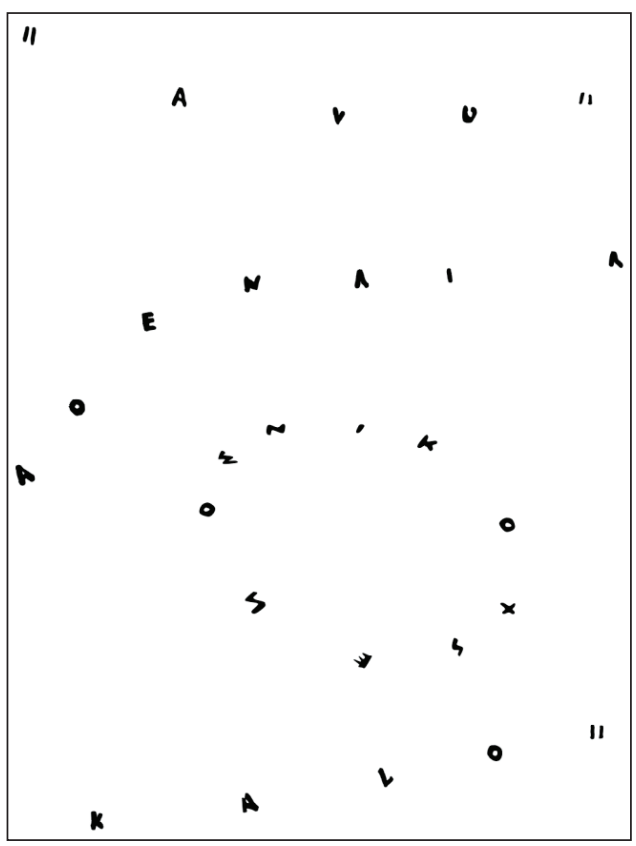


Na mesma face, há o nome Nikoxsenos em destaque (em verniz negro), associado a um cão no escudo, e à esquerda, em tinta rubra, há a palavra kalos grafada equivocadamente (iialoii). Esse tipo de inscrição era bastante comum: trata-se das chamadas inscrições de homenagem integradas ao universo da pederastia em Atenas, destacando o nome de um jovem ateniense e a palavra "belo", ${ }^{19}$ neste caso, "Nicóxeno é belo". E, como o vaso não foi assinado, Beazley propôs no nome do pintor a partir dessa informação (ver nota 14). Na outra face, também grafada de forma equivocada, novamente aparece, à esquerda, a palavra kaloii (kalos), reforçando a homenagem (ver Figuras 1 e 5).

Tais inscrições, associadas às imagens, indicam que o conjunto de referências apresentadas no vaso (forma, imagens e inscrições) era essencialmente ligado ao universo ático. Considerando que o vaso foi encontrado na região da Campânia, na etrusca Cápua, parece que os artesãos que produziam tais vasos não controlavam efetivamente o destino de parte de sua produção, já que, se o conjunto de mensagens apresentadas pelo Pintor de Nicóxeno pressupunha um interlocutor para a sua compreensão, longe da região da Ática, dificilmente tais imagens e inscrições poderiam ser compreendidas em sua profundidade. Ou seja, tais informações dependiam de certa familiaridade com referências locais, tanto diacrônicas (é o caso da compreensão das imagens relacionadas à tradição do modelo panatenaico), como sincrônicas (a referência a um rapaz da região); situação que parece ter sido recorrente a julgar pela grande quantidade de vasos áticos com informações muito precisas e referenciadas localmente, entretanto encontrados em contexto etrusco.

\section{CONSIDERAÇÕES FINAIS}

No repertório de conceitos das narrativas globais aparecem ideias como colonização, redes (e seus nós) e globalização, que orientam a observação de movimentos amplos que explicariam, por exemplo, os enquadramentos gerais da produção, circulação e recepção dos vasos áticos. A ideia de Arqueologia da Imagem, como aqui proposta, apresenta elementos precisos para informar as grandes narrativas, considerando-se também a natureza desses contatos. Assim, é interessante notar que, por mais que as redes comerciais conectassem povos de diferentes regiões do Mediterrâneo no contexto em que esse vaso foi produzido e exportado para a região da Etrúria, a circulação desses objetos os integrava a contextos nos quais os significados poderiam ser distantes daqueles propostos pelos produtores das imagens. 
Ou seja, no que se refere às imagens em contexto de um Mediterrâneo globalizado, elas parecem indicar, em determinadas situações, que a integração não uniformizava a relação entre povos específicos e o universo material ao seu redor. Portanto, o significado da imagem poderia ser pensado nesse quadro complexo de situações que envolvia suas especificidades materiais, circulação e recepção. Não se pode atribuir naturalmente a imagens produzidas na Ática um significado ático; são as redes de relações complexas do Mediterrâneo antigo que indicam o efetivo significado das imagens contextualizadas.

\section{REFERENNCIAS}

BELLAN, Gilles. Archéologie sous influence: retours d'expérience. Tétralogiques, n. 23, p. 33-46, 2018.

BIERL, Anton. Maenadism as self-referencial chorally in Euripides' Bacchae. In: GAGNÉ, Renaud; HOPMAN, Marianne G. (ed.). Choral Mediations in Greek Tragedy. [s.l.]: Cambridge University Press, 2013, p. 211-226.

BRUNEAU, Philippe. De l'image. RAMAGE - Revue d'Archéologie Moderne et d'Archéologie Générale, v. 4, p. 249-295, 1986.

BRUNEAU, Philippe. L'épigraphie moderne et contemporaine. RAMAGE - Revue d'Archéologie Moderne et d'Archéologie Générale, v. 6, p. 13-40, 1988.

BRUNEAU, Philippe; BALUT, Pierre-Yves. Artistique et archéologie. Paris: Presses de l'Université de Paris-Sorbonne, 1997.

BÜCHSEL, Martin. Die Entstehung des Christusporträts: Bildarchäologie statt Bildhypnose. Mainz am Rhein: Philipp von Wabern, 2003.

CERQUEIRA, Fabio Vergara. Tradições visuais orais e literárias: conformação da memória e constituição de referenciais materiais de identidade (a narrativa da contenda musical entre Apolo e Mársias). Phoînix, v. 20, n.1, p. 81-111, 2012.

CHÉREL, Emmanuelle; SAUSSIER, Gilles. Retourner l'actualité, une lecture du Tableau de chasse. In: MOREL, Gaëlle (dir.). Photojournalisme et art contemporain: les derniers tableaux. Paris: Éd. des Archives Contemporaines, 2008. p. 25-45.

CIASTELlARDI, Matteo; ALMEIDA, Cristina M. de; SCOLARI, Carlos A. (ed.). McLuhan Galaxy Conference. Understanding Media, Today. Barcelona, May, 23rd-25th. (Conference Proceedings). Barcelona: Ed. Universidad Oberta de Catalunya, 2011.

CLIFFORD, K. E. Lingering Words: A Study of Ancient Greek Inscriptions on Attic Vases. 2007. PhD Thesis - Department of Classics, Master of Arts, The Florida State University. Tallahassee, 2007.

COHEN, Olivia-Jeanne. Modes de représentation du sujet lyrique chez Baudelaire (référence: "Un Fantôme", Les Fleurs du Mal). In: AURAIX-JONCHIÈRE, Pascale 
(org.). Écrire la peinture entre XVIIIe et XIXe siècles. Actes du Colloque du Centre de Recherches Révolutionnaires et Romantiques de l'Université Blaise-Pascal (Clermont-Ferrand, 24, 25, 26 oct. 2001). Clermont-Ferrand: Presses Universitaires Blaise Pascal, 2003. p. 385-392.

CONRAD, Sebastian. What is Global History? Princeton, NJ: Princeton University Press, 2017.

CÓRDOVA, Carlos. Arqueología de la imagen: México en las vistas estereoscópicas. Mexico, D.F.: Museo de la Historia Mexicana, 2000.

DESPRÉS-LONNET, Marie. La documentation photographique d'un site culturel, fabrique d'Athipies. Communication \& langages, n. 180, p. 31-46, 2014.

DONOHUE, Alice A. Greek Sculpture and the Problem of Description. [s.l.]: Cambridge University Press, 2005.

DUBOIS, Page. Centaurs and Amazons: Women and the Pre-History of the Great Chain of Being. Ann Arbor: University of Michigan Press, 1991.

FETZER, Anita. Contexts in Interaction: Relating Pragmatic Wastebaskets. In: FINKBEINER, Rita; MEIBAUER, Jörg; SCHUMACHER, Petra B. (ed.). What is a Context? Linguistic Approaches and Challenges. Amsterdam: John Benjamins Publ., 2012. p. 105-128.

FRANCISCO, Gilberto da S. Ânforas panatenaicas e paisagens estruturais. Mare Nostrum, n. 4, p. 81-99, 2013.

FRANCISCO, Gilberto da S. Um artista grego na Etrúria? O caso de Aristonoto. Diálogos Mediterrânicos, v. 10, p. 26-47, 2016.

FRANCISCO, Gilberto da S. Panatenaicas: tradição, permanência e derivação. 2012. Tese (Doutorado) - Museu de Arqueologia e Etnologia da Universidade de São Paulo (MAE-USP). São Paulo, 2012.

GASCHÉ, Rodolphe. The Honor of Thinking: Critique, Theory, Philosophy. Palo Alto: Stanford University Press, 2007.

GELL, Alfred. Art and Agency: An Anthropological Theory. Oxford: Clarendon Press, 1998.

GILL, David W. J.; VICKERS, Michael. They were expendable: Greek Vases in the Etruscan Tomb. Révue des Études Anciennes, v. 97, n. 1-2, p. 225-249, 1995.

GRILLO, José Geraldo C. A Guerra de Troia no imaginário ateniense: sua representação nos vasos áticos dos séculos VI-V a.C. 2009. Tese (Doutorado) - Museu de Arqueologia e Etnologia da Universidade de São Paulo (MAE-USP). São Paulo, 2009.

HÄGG, Robin (ed.). The Iconography of Greek Cult in the Archaic and Classical Periods: Proceedings of the First International Seminar on Ancient Greek Cult, organised by the Swedish Institute at Athens and the European Cultural Centre of Delphi (Delphi, 16-18 Nov. 1990). Liège: Kernos suppléments, 1992. 
HODDER, Ian et al. The Archaeology of Contextual Meanings. Cambridge: Cambridge University Press, 1987.

HODOS, Tamar (ed.). The Routledge Handbook of Archaeology and Globalization. London: Routledge, 2016.

HÖLSCHER, Tonio. The Language of Images in Roman Art. Cambridge: Cambridge University Press, 2004.

ISLER-KERÉNYI, Cornelia. Civilizing Violence: Satyrs on 6th-century Greek Vases. Fribourg: Saint-Paul, 2004.

JAMESON, Michael H. Cults and Rites in Ancient Greece: Essays on Religion and Society. Cambridge: Cambridge University Press, 2014.

JUNCA, John Alonso. Ensayos visuales críticos: diálogos entre la fotografía y la reflexión. In: RAMOS DELGADO, David. Miradas caleidoscópicas: educación artística visual en las culturas contemporáneas. Bogotá: Universidad Pedagógica Nacional, 2019.

JUNKER, Klaus. Interpreting the Images of Greek Myths: An Introduction. Cambridge: Cambridge University Press, 2012.

KAHIL, Lilly; AUGÉ, Christian; LINANT DE BELLEFONDS, Pascale (éd.). 『Iconographie classique et identités régionales: Colloque International, Paris, 26 et 27 mai 1983. खParis: Diffusion de Boccard, 1986.

KOSMOPOULOU, Angeliki. The Iconography of Sculptured Statue Bases in the Archaic and Classical Periods. Madison: University of Wisconsin Press, 2002.

KUNZE, Christian. Formal Approaches. In: MARCONI, Clemente (ed.). The Oxford Handbook of Greek and Roman Art and Architecture. [s.l.] Oxford University Press, 2014. p. 541-556.

LEAR, Andrew. Kalos-inscriptions. In: LEAR, Andrew; CANTARELLA, Eva. Images of Ancient Greek Pederasty: Boys were Their Gods. London: Routledge, 2009. p. 164-173.

LESSA, Fabio de S. O feminino em Atenas. Rio de Janeiro: Mauad, 2004.

LOGAN, Robert K. Understanding New Media: Extending Marshall McLuhan. New York: Peter Lang, 2010.

NEILS, Jenifer. Goddess and Polis: The Panathenaic Festival in Ancient Athens. Princeton, NJ: Princeton University Press, 1992.

OBERSCHELP, Walter. Bild und Wirklichkeit. In: GROSS, Dominik; WESTERMANN, Stefanie (ed.). Vom Bild zur Erkenntnis? Visualisierungskonzepte in den Wissenschaften. Kassel: Kassel University Press GmbH, 2007. p. 29-46.

PANOFSKY, Erwin. Iconografia e iconologia uma introdução ao estudo da arte da renascença. In: PANOFSKY, Erwin. Significado nas artes visuais. São Paulo: Perspectiva, 1976.

PICARD, Charles. Méthodes et débats de l'iconographie classique. Revue des Études Anciennes, v. 37, n. 4, p. 468-478, 1935. 
REDE, Marcelo. Iconografia, história e antigüidade grega I: tendências gerais. Anais do Museu Paulista: História e Cultura Material, v. 1, n. 1, p. 263-285, 1993.

ROBERTSON, Martin. The Art of Vase-Painting in Classical Athens. Cambridge: Cambridge University Press, 1992.

ROCHA-PEREIRA, Maria H. O estatuto social dos artistas gregos. Revista do Museu de Arqueologia e Etnologia da Universidade de São Paulo, São Paulo, v. 4, p. 95-101, 1994.

SARIAN, Haiganuch. Arqueologia da imagem: aspectos teóricos e metodológicos na iconografia de Héstia. Revista do Museu de Arqueologia e Etnologia da USP, Suplemento 3, p. 69-84, 1999.

SARIAN, Haiganuch. Arqueologia da imagem: expressões do mito e da religião na antiguidade clássica. 2005. Tese (Livre docência em Arqueologia Clássica) - Museu de Arqueologia e Etnologia da Universidade de São Paulo (MAE-USP). São Paulo, 2005.

SARIAN, Haiganuch. Corpus Vasorum Antiquorum (CVA). Classica: Revista Brasileira de Estudos Clássicos, n. 11/12, p. 349-363, 1998/1999.

SARIAN, Haiganuch. Lexicon Iconographicum Mythologiae Classicae. Revista do Museu de Arqueologia e Etnologia da USP, v. 6, p. 384-386, 1996.

SARIAN, Haiganuch. Poieîn-graphein: o estatuto social do artesão-artista de vasos áticos. Revista do Museu de Arqueologia e Etnologia da Universidade de São Paulo, São Paulo, v. 3, p. 69-84, 1993.

SARIAN, Haiganuch. Reflexões sobre o Mundo Grego e o Antigo Oriente Próximo. (Entrevista). Heródoto, Guarulhos: Unifesp, v. 2, n. 1, p. 3-25, 2017.

SCHIFFER, Michael B. Archaeological Context and Systemic Context. American Antiquity, v. 37, n. 2, p. 156-165, 1972.

SCHIFFER, Michael B. Behavioral Archaeology: Principles and Practice. London: Routledge, 2014.

SHAW, Ian; JAMESON, Robert. A Dictionary of Archaeology. Oxford: Blackwell, 2002. SNODGRASS, Anthony. Homer and the Artists: Text and Picture in Early Greek Art. Cambridge: Cambridge University Press, 1998.

SPERLING, Jutta Gisela. Roman Charity: Queer Lactations in Early Modern Visual Culture. Bielefeld: Transcript Verlag, 2016.

SPIVEY, Nigel. Greek vases in Etruria. In: RASMUSSEN, Tom B.; SPIVEY, Nigel. Looking at Greek vases. Cambridge: Cambridge University Press, 1991. p. 131-150.

VISAGIE, Johann. Argeologiese beeldsemiotiek en skilderkuns. Acta Academica, v. 32, n. 3, p. 42-72, 2000.

WEBB, David. Foucault's Archaeology: Science and transformation. Edinburgh: Edinburgh University Press, 2013. 
YELLES, Anissa. Les débuts de l'archéologie de l'image au XIXe siècle. Jules de Laurière (1825-1894), pionnier du genre en France. Les nouvelles de l'archéologie, n. 155, p. $18-22,2019$.

\section{NOTAS}

${ }^{1}$ Os autores deste artigo contaram com o apoio das seguintes instituições nacionais e internacionais: Capes, CNPq, Fapesp, Unifesp, Alexander von Humboldt Foundation (Alemanha) e École française d'Athènes (Grécia).

${ }^{2}$ Tal campo vem se estruturando ao longo dos séculos XX e XXI. Algumas publicações antigas apresentavam sínteses do debate (PICARD, 1935), mas, ao longo dos anos $1980 \mathrm{e}$ 1990, o interesse parece ter se focalizado, o que se indica por uma série de publicações e colóquios sobre o tema, como Kahil; Augé; Linant de Bellefonds, 1986, e Hägg, 1992 (para uma síntese do cenário, ver Rede, 1993), e dossiês mais recentes, com o intuito de apresentar as tendências das pesquisas atuais, como o volume 75, de 2007, da revista Pallas (Revue d'Études Antiques), intitulado Chronique d'Iconographie Antique, bem como estudos monográficos, por exemplo, Kosmopoulou, 2002.

${ }^{3}$ Para a apresentação desse cenário, ver Aldrovandi, 2009, p. 40-43.

${ }^{4}$ Ver verbetes archaiología e arché em Liddell-Scott-Jones Lexicon of Classical Greek.

${ }^{5}$ Para um debate sobre a arqueologia de Foucault, ver Gasché, 2007, p. 211-249, e Webb, 2013.

${ }^{6}$ Para a síntese das reflexões desses autores, ver Bruneau; Balut, 1997.

${ }^{7}$ Para a apresentação dos três níveis, ver Panofsky, 1976, p. 47-64; para a apresentação das limitações da descrição pré-iconográfica, ver p. 55-58.

${ }^{8}$ Para os diálogos entre a Iconografia Clássica e as propostas de Panofsky, ver também Dubois, 1991, p. 71-72; 157-158; Hölscher, 2004, p. xxii-xix; Isler-Kerényi, 2004, p. vii; Junker, 2012, p. 124-125; Sperling, 2016, p. 12, 88 e 251; e Elsner, 2018, p. 386.

${ }^{9}$ A noção de medium de McLuhan aparece explicitamente em poucos estudos de Iconografia Clássica. Ver, por exemplo, Kunze, 2014, p. 551-552. Ver também Bierl, 2013, p. 226, para o uso do conceito em uma reflexão sobre os coros na performance do teatro.

${ }^{10}$ Por exemplo, para o estatuto social de artistas/artesãos gregos antigos, ver Sarian, 1993; Rocha-Pereira, 1994; Francisco, 2016, p. 30-32.

${ }^{11}$ Para o contexto sistêmico, ver Schiffer, 2014; Shaw; Jameson, 2002, p. 113, verbete behavioural archaeology, behaviorismo; para a recuperação do contexto histórico na pesquisa arqueológica, ver Hodder, 1987; Shaw; Jameson, 2002, p. 175-176, verbete contextual archaeology; para o contexto arqueológico, ver Schiffer, 1972; 2014, p. 22-31.

${ }^{12}$ Por exemplo, as descrições das esculturas monumentais de Atena na Acrópole de Atenas feitas por Pausânias (a Atena Parthenos e a Atena Promakhos - Pausânias 1.24.5-7 e 
1.28.2); e a estátua de culto de Hera no Heraion de Argos, também descrita por Pausânias (2.17.4).

${ }^{13}$ Nesse âmbito, note-se que havia modelos e esquemas imagéticos que também circulavam. Por exemplo, ver Sarian, 2005, p. 79-118, e Sarian, 2017, p. 18-20, para a formulação do esquema figurativo de Perseu decapitando a Górgona, que teve origem mesopotâmica (Gilgamesh decapitando Humbaba); e Sarian, 2005, p. 183-211, e Sarian, 2017, p. 11-13, para o esquema figurativo do Mitra tauróctono, caracterizado por aspectos estéticos propriamente gregos, apesar da pouca influência do mitraísmo em ambiente grego.

${ }^{14}$ Resumidamente, as ideias sobre os aspectos globais da história aqui apresentados são inspiradas nas obras de Sebastian Conrad (2017) e Tamar Hodos (2016), principalmente o capítulo "The Global Mediterranean. A material-cultural perspective”, por Miguel J. Versluys (p. 597-601), e "Classical connections and Mediterranean practises: exploring connectivity and local interactions”, por Peter van Dommelen (p. 618-635).

${ }^{15}$ Para o Pintor de Nicóxeno, ver Robertson, 1992, p. 118-121 (ver especialmente p. 118, para o nome do artesão). Para a apresentação do vaso, ver Corpus Vasorum Antiquorum, Robinson Collection 2, USA 6, 22-23, pl. 24, 1a-b, 25; e Beazley $A R V^{2}, 221$, no. 6.

${ }^{16}$ Para uma apresentação geral das ânforas panatenaicas, ver Francisco, 2012.

${ }^{17}$ Considerando que os sacrifícios antes do combate eram comuns (JAMESON, 2014, p. 98-126) e que havia uma extensa iconografia de partida de guerreiros (GRILLO, 2009, p. 55-82), parece que as duas cenas seriam ligadas a um movimento anterior ao combate.

${ }^{18}$ Atena diante de altar e entre colunas (Boston, Museum of Fine Arts, 95.19); Atena citareda diante de altar e entre colunas (Berlin, Antikensammlung, F2161); Atena Promakhos entre colunas (Munich, Antikensammlungen: 8728); Atena diante de altar (Paris, Musée du Louvre, G60 e G61); e uma variante com Hermes diante de altar e entre colunas (Zurique, coleção privada - Beazley, ARV 221.8BIS). Todos esses vasos são ânforas de tipo panatenaico em figuras vermelhas e atribuídos ao Pintor de Nicóxeno.

${ }^{19}$ Para as inscrições de tipo kalos, ver Clifford, 2007, p. 15-25, e Lear, 2009.

Artigo recebido em 2 de março de 2020. Aprovado em 25 de maio de 2020. 